Pediatr Surg Int (1990) 5: 302-306

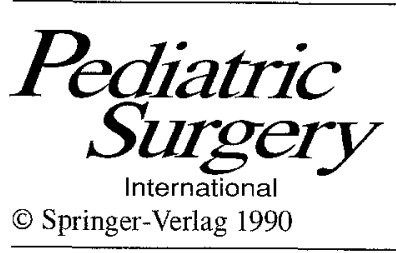

\title{
Extracorporeal life support (ECLS) for pediatric trauma: experience with five cases
}

\author{
Harry L. Anderson, III, Arnold G. Coran, David J. Schmeling, Robert J Attori, Keith T. Oldham, \\ Robin A. Chapman, and Robert H. Bartlett
}

Section of Pediatric Surgery, C. S. Mott Children's Hospital and the Section of General Surgery, University of Michigan Medical School, Ann Arbor, MI 48 109-0245, USA

\begin{abstract}
Extracorporeal life support (ECLS) was used to treat five pediatric trauma patients (ages 1 to 17 years) with respiratory failure unresponsive to conventional mechanical ventilation. Diagnoses in these patients that resulted in respiratory failure included hydrocarbon aspiration (one patient), multiple trauma with pulmonary contusion (two patients), bronchopleural fistula (one patient), and neardrowning (one patient). Time on ECLS bypass averaged $328 \mathrm{~h}$ (range 140-527 h). Physiologic complications included bleeding, cardiac arrest, cardiac tamponade, hypoxemia, and hypotension. Mechanical complications involving the bypass circuit included roller-pump raceway rupture, roller-pump failure, and membrane oxygenator failure. All complications were managed without mortality. Three of the five patients were decannulated from ECLS and survived. Support was terminated in the remaining two due to irreversibility of the pulmonary injury. ECLS may provide life-saving support to pediatric patients with respiratory failure after trauma when conventional means of ventilatory support have failed.
\end{abstract}

\section{Introduction}

Extracorporeal life support (ECLS), which includes extracorporeal membrane oxygenation (ECMO), has been used for over 20 years in the treatment of cardiorespiratory failure unresponsive to conventional mechanical ventilation. ECLS support has been used in the treatment of over 3000 cases of neonatal respiratory failure [5], and recently has gained popularity in the treatment of cardiorespiratory failure in pediatric and adult patients.

The pediatric trauma patient may have reversible respiratory failure resulting from pulmonary contusion, respiratory distress syndrome or capillary leak phenomena, bronchopleural fistula, or inhalational injury due to organic

Offprint requests to: G. Coran compound aspiration or smoke. This age group presents special problems with regard to the selection for and institution of ECLS bypass. Entry criteria for ECLS based on historical mortality in pediatric patients have not formally been described [2]. In addition, pediatric trauma patients with injuries resulting from blunt or penetrating force are at much greater risk for bleeding with systemic heparinization. Therefore, the decision to institute ECLS bypass in the pediatric trauma patient needs to be made with these considerations in mind.

To date, only isolated cases of ECLS support of pediatric trauma patients have appeared in the literature $[2,4,7$, $9,12,13,15]$. In this report, we will present in detail one pediatric trauma patient supported by ECLS bypass and summarize our experience with five such cases of ECLS support after trauma.

\section{Patients and methods}

Patients were selected for ECLS bypass between May 1987 and December 1989. All patients were referred to, or were initially evaluated and managed at, the University of Michigan Medical Center. Selection of patients was individualized based on age, time on mechanical ventilation prior to ECLS bypass, and degree of respiratory failure based on ventilator settings, arterial blood gases, and radiologic appearance of the chest $\mathrm{X}$-rayfilm. All had respiratory failure unresponsive to conventional mechanical ventilation as evidenced by hypoxemia, hypercarbia, and/or acidosis. Patients were excluded when major central nervous system injury, long-term prior mechanical ventilation and suspected irreversible lung damage or fibrosis, or a contraindication to systemic heparinization was present. After informed consent was obtained from the family, cannulation was performed under local anesthesia at the bedside using venoarterial or venovenous access (right internal jugular vein for venous drainage, with perfusion performed via cannulation of the right common carotid artery during venoarterial bypass or cannulation of the femoral vein at the saphenofemoral junction for venovenous bypass). A typical venovenous circuit is shown in Fig. 1. Once on bypass, ventilator settings were rapidly decreased to low airway pressures, rates, and $\mathrm{FiO}_{2}$ levels. These typically included an $\mathrm{FiO}_{2}$ of $30 \%-40 \%$, a rate of $10 / \mathrm{min}$, and peak airway pressures of less than $25-30 \mathrm{~cm} \mathrm{H}_{2} \mathrm{O}$. Hematocrit was maintained at $40 \%-45 \%$ and the platelet count was maintained obove $100,000 / \mathrm{mm}^{3}$ by transfusion. Activated clotting time (ACT) was maintained between 180 and $220 \mathrm{~s}$ (normal $100 \mathrm{~s}$ ). 


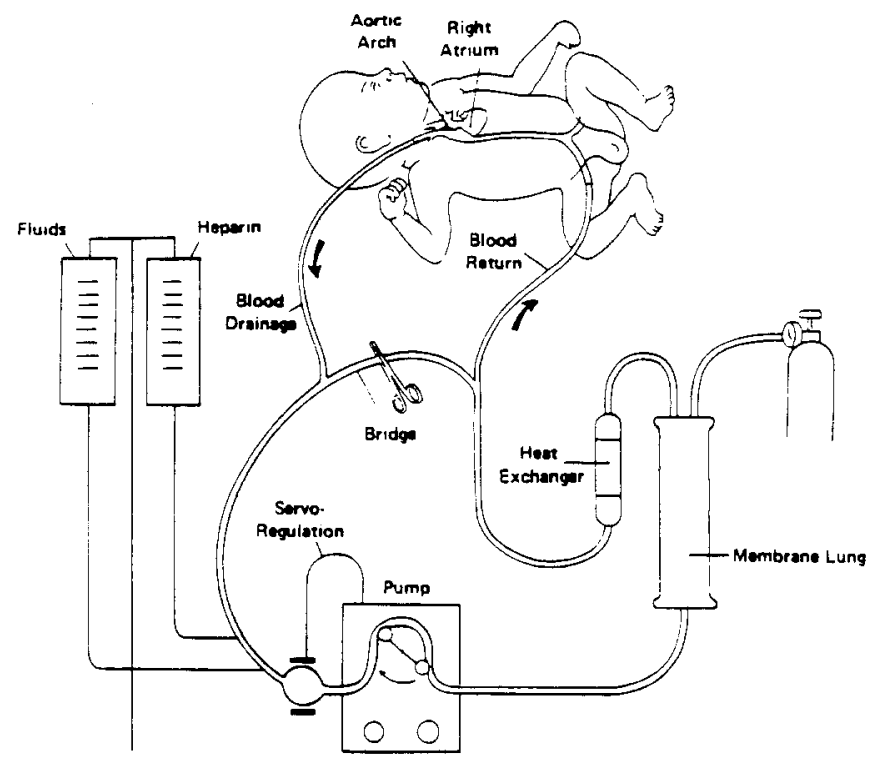

Fig. 1. Schematic diagram of typical venovenous ECLS circuit
Bypass flow was initially maintained at $75-100 \mathrm{ml} / \mathrm{kg}$ per minute. Weaning from venoarterial bypass was based on improvement in mixedvenous blood oxygen saturation $\left(\mathrm{SVO}_{2}\right)$ as measured by a fiberoptic Oximetrix catheter in the venous drainage line of the circuit. Weaning from venovenous bypass was based on improvement in arterial blood gases. Decannulation was performed when oxygenation and ventilation were adequate at acceptably low ventilator settings while bypass cannulae were clamped ("trial off"). Catheters were then removed and the neck vessels ligated; the femoral vein was usually repaired by oversewing the saphenofemoral junction.

\section{Case report (Fig. 2a-d)}

A 2-year-old, 13-kg female pedestrian was run over by an automobile. She sustained a crush injury to her left chest. She was initially transported to a local hospital where a chest tube was placed for a left tension pneumothorax. The patient was intubated, stabilized, and transported via helicopter to the University of Michigan Medical Center. On further evaluation, injuries included a mild, non-focal, closed head injury, a left 2 nd rib fracture, the treated left
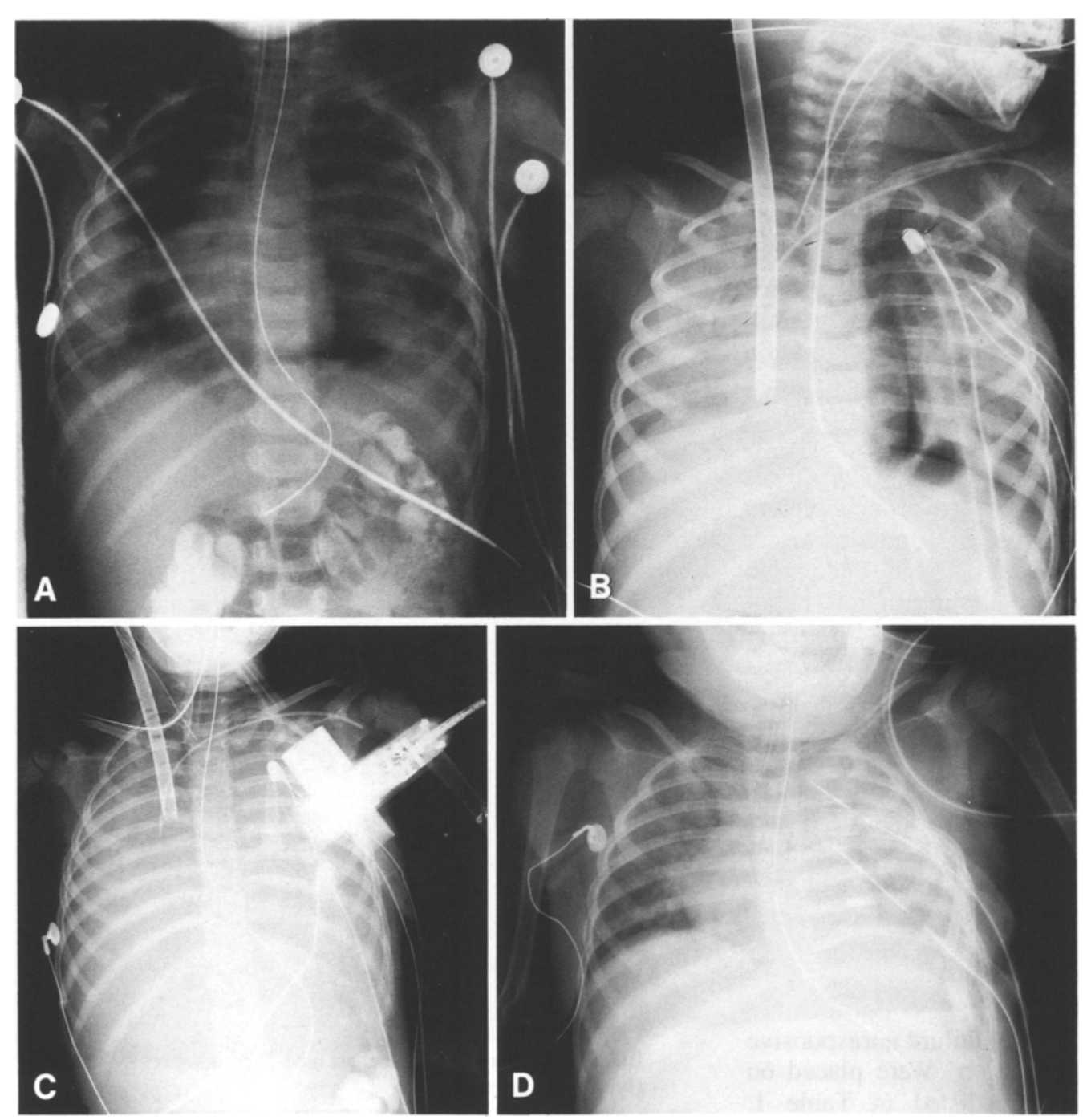

Fig. 2. Serial chest radiographs of patient 5 before, during, and after ECLS bypass. a Initial radiograph performed on admission to hospital. Nasogastric tube, endotracheal tube, and left chest tube are in place. Opacification of both lung fields is the result of pulmonary contusion. b Radiograph performed immediately after cannulation for venovenous ECLS. Pulmonary function has deteriorated and the right lung field has become more opacified. Right internal jugular venous drainage catheter is shown in place. A central venous catheter and two additional left chest tubes have been inserted. A left pneumothorax persists (bronchopleural fistula). c After 5 days on bypass, the lung fields are nearly radiopaque. The venous drainage catheter had advanced out of the chest and required repositioning in the right atrium. Left thoracotomy and lower lobectomy was performed on day 6 for persistent, uncontrolled bronchopleural fistula. d Two weeks after decannulation. An andotracheal tube, nasogastric tube, and two chest tubes remain in place. Some aeration of the left lung field is seen. The patient was extubated 3 weeks after the conclusion of ECLS bypass. 
Table 1. ECLS for respiratory failure in pediatric trauma

\begin{tabular}{|c|c|c|c|c|c|c|c|}
\hline \multicolumn{2}{|l|}{ Patient } & \multirow{2}{*}{$\begin{array}{l}\begin{array}{l}\text { Age } \\
\text { years }\end{array} \\
1\end{array}$} & \multirow{2}{*}{$\begin{array}{l}\text { Diagnosis } \\
\text { Hydrocarbon aspiration }\end{array}$} & \multirow{2}{*}{$\begin{array}{l}\begin{array}{l}\text { Survived/ } \\
\text { died }\end{array} \\
\text { Survived }\end{array}$} & \multirow{2}{*}{$\begin{array}{l}\text { Mode of } \\
\text { bypass }\end{array}$} & \multirow{2}{*}{$\begin{array}{l}\begin{array}{l}\text { Bypass } \\
\text { time }(\mathrm{h})\end{array} \\
140\end{array}$} & \multirow{2}{*}{$\frac{\begin{array}{l}\text { Days intubated } \\
\text { prior to ECLS }\end{array}}{4}$} \\
\hline 1 & MS & & & & & & \\
\hline 3 & JW & 17 & Pulmonary contusion/multiple trauma & Died & VV & 314 & 19 \\
\hline 4 & SS & 4 & Near-drowning/multiple trauma & Survived & VV & 297 & 9 \\
\hline 5 & RR & 2 & Bronchopleural fistula/multiple trauma & Survived & $V V->V A$ & 363 & 2 \\
\hline
\end{tabular}

VA, Venoarterial; VV, venovenous

tension pneumothorax, left bronchopleural fistula with pulmonary contusion, suspected hepatic contusion (AST 857 IU/1, ALT 372 IU/1, amylase 305 IU/1), and renal contusion (urinalysis with $>100$ RBC per high-power field).

She was admitted to the pediatric intensive care unit and mechanical ventilation was instituted. Initial ventilator settings were: $\mathrm{FiO}_{2}=1.0$, tidal volume $=150 \mathrm{ml}$ $(11 \mathrm{ml} / \mathrm{kg})$, rate $=20 / \mathrm{min}$, and positive end-expiratory pressure $=4 \mathrm{~cm} \mathrm{H}_{2} \mathrm{O}$. Initially, the level of support was weaned to $\mathrm{FiO}_{2}=0.35$ and rate $18 / \mathrm{min}$. However, progressive deterioration in pulmonary function occurred over the next $36 \mathrm{~h}$ requiring increases to $\mathrm{FiO}_{2}=1.0$, rate $=80 / \mathrm{min}$, inspiratory pressure $=35 \mathrm{~cm} \mathrm{H} 2 \mathrm{O}$, with arterial blood gases of $\mathrm{pO}_{2}=51 \mathrm{mmHg}, \mathrm{pCO}_{2}=67 \mathrm{mmHg}$, and $\mathrm{pH}=7.18$. She was placed on venovenous ECLS (right internal jugular vein drainage, right femoral vein reinfusion). Initially the patient became hypotensive during institution of bypass, however she responded to volume expansion and dopamine infusion. Bypass pump flow was $1.4 \mathrm{l} / \mathrm{min}$. Hypotension recurred and did not regress with volume, dopamine, or dobutamine infusion. The patient was therefore converted to venoarterial bypass utilizing the previously dissected right common carotid artery after $2 \mathrm{~h}$ of venovenous perfusion. During bypass, bleeding from the cervical cannulation site necessitated exploration and cauterization of muscular bleeding vessels. She required continuous sedation (midazolam infusion) and paralysis during the bypass run. After 6 days on bypass she underwent left thoracotomy and debridement left lower lobectomy for a persistent, uncontrolled bronchopleural fistula. Postoperatively, ongoing bleeding and a recurrent left hemothorax necessitated re-exploration $24 \mathrm{~h}$ later. No surgical bleeding sites were identified; bleeding was controlled by fibrin glue and decreasing the level of systemic heparinization. After 15 days on bypass ECLS flow was weaned to $0.51 / \mathrm{min}$ and a trial off bypass was successful using minimal ventilator settings.

The hospital course after ECLS bypass included maintenance of intravenous antibiotics, parenteral alimentation, and weaning and extubation from the ventilator 23 days after decannulation. She was transferred to the rehabilitation service and ultimately discharged from the hospital.

\section{Results}

Five trauma patients with respiratory failure unresponsive to conventional mechanical ventilation were placed on ECLS bypass. The diagnoses are listed in Table 1.
Venovenous bypass was initially used in four of the five patients. Two of these four patients required conversion to venoarterial bypass because of inadequate support on venovenous bypass (hypoxemia, hypotension). In both patients this was achieved by cannulation of the previously dissected carotid artery.

All patients experienced bleeding while on bypass, most often from the cervical cannulation site or chest tube insertion sites. This complication was managed by surgical exploration of the wound or site after hypofibrinogenemia had been ruled out or corrected and platelet counts were more than $100,000 / \mathrm{mm}^{3}$. The ACT was maintained in the $170-190 \mathrm{~s}$ range. All other complications, both physiologic and mechanical, were managed without morbidity or mortality (Table 2 ).

The two non-survivors developed irreversible injuries during their ECLS course. Patient 3 was placed on ECLS bypass after 19 days of mechanical ventilation and required termination of bypass due to progressive pulmonary fibrosis, as evidenced by suprasystemic pulmonary artery pressures after 2 weeks of ECLS bypass. Patient 2 had not recovered sufficient pulmonary gas exchange to support life when bleeding complications at $527 \mathrm{~h}$ (22 days) required termination of bypass.

Patient 4 demonstrated opacification of the right hemithorax at 4 days of ECLS bypass, presumably secondary to a hemothorax. Exploratory thoracotomy, however, revealed intraparenchymal pulmonary hemorrhage that was initially thought to be of sufficient magnitude to preclude pulmonary recovery. Because of the absence of other life-threatening complications bypass was nevertheless continued, and the patient was weaned from bypass at 12 days, was decannulated, and eventually was discharged from the hospital.

Table 2. Complications during ECLS bypass

\footnotetext{
Mechanical complications

- Raceway rupture

- Oxygenator failure (clotting, blood leak)

- Roller-pump failure

Physiologic complications

- Pericardial tamponade

- Cardiac arrest

- Bleeding (cannulation sites, chest tubes, hemothorax)

- Hypoxemia, hypotension
} 


\section{Discussion}

This report summarizes the results of ECLS for five pediatric trauma patients with potentially reversible respiratory failure. Criteria for institution of ECLS for neonatal $[1,8]$ and adult patients $[1,2,8,14,16]$ have been previously described. The pediatric age group has yet to have specific criteria developed for the use of ECLS bypass for respiratory failure.

There are scattered case reports of the use of ECLS bypass for pediatric trauma patients $[2,4,7,9,12,13,15]$. Results of ECLS bypass for pediatric respiratory and cardiac failure from all causes indicate a survival rate approaching $50 \%$, similar to that in adult patients with respiratory distress syndrome (ARDS) reported at other centers $[11,14]$. These results have been promising and are much improved over the original multicenter adult ECMO trial, where survival was essentially the same in patients treated with conventional mechanical ventilation and ECMO ( $8.3 \%$ vs $9.5 \%$ ) [16]. The increase in current-day ECLS survival is likely due to earlier institution of bypass, improvements in the conduct of ECLS bypass, and low-pressure, low-rate ventilation while on ECLS bypass $[8,11,13$, $14,16]$.

Selection of patients at our institution is individualized based on a case-by-case evaluation. Exclusionary criteria include central nervous system injury and predictably lethal associated problems. The presence of irreversible lung damage or fibrosis has been more difficult to determine. We currently exclude patients who have undergone mechanical ventilation for longer than 10 days prior to referral for ECLS bypass. Early lung biopsy may differentiate reversible and irreversible pulmonary injury. In this series, patients 2 and 3 developed irreversible pulmonary fibrosis as evidenced by failure of transpulmonary gas exchange with a clear chest X-rayfilm or the presence of suprasystemic pulmonary artery pressures. Previously, our practice for assessing irreversibility was to perform open lung biopsy on patients still on bypass after 2 weeks if they showed no signs of pulmonary improvement. At present, we continue bypass beyond 2 weeks for patients who demonstrate no contraindication to further bypass (major bleeding, intracerebral hemorrhage, or major organ system failure) without lung biopsy.

A notable feature of the history in the surviving patients was a shorter period of mechanical ventilation prior to bypass than for the nonsurvivors. Similar observations have been made by others in adult patients undergoing ECLS bypass $[8,11,14]$.

All patients experienced bleeding during bypass. All except patient 1 underwent ECLS bypass with indwelling chest tubes, and exploration of chest tube sites for bleeding was routinely necessary. Performance of tube thoracostomy during ECLS bypass with systemic heparinization is potentially hazardous, but the risks can be reduced by the judicious use of electrocautery and fibrin glue during and after placement [10]. Patient 5 was converted from venovenous to venoarterial bypass because of cardiac arrest and loss of systemic blood pressure. This sequence emphasizes the importance of establishing that cardiac function is near normal prior to the decision to utilize venovenous bypass. Venoarterial bypass is preferable when obvious or potential cardiac dysfunction is present as evidenced by hypotension, oliguria, acidosis, or assessment of cardiac contractility by echocardiogram.

Ongoing advancement in ECLS and ventilator management should improve the survival of pediatric trauma patients and other patients with respiratory failure undergoing ECLS bypass. In the pediatric trauma patient, multisystem injury adds to the complexity of management in contrast to ECLS support of neonates for respiratory system failure. In particular, the use of heparin-bonded circuitry will minimize, if not eliminate, systemic anticoagulation with heparin, thus decreasing bleeding complications and the need for blood product replacement; operative intervention while on bypass will also be easier to perform with a decreased risk of bleeding. ECLS circuits that fill passively will require less "technical supervision" and will be less likely to result in tubing rupture due to high pressure or cavitation at the roller pump.

\section{Conclusion}

Five pediatric trauma patients with respiratory failure unresponsive to conventional mechanical ventilation were placed on ECLS. Bleeding occurred as a complication in all cases. All physiologic and mechanical complications were managed without morbidity or mortality. Three of the five patients were decannulated and survived. Treatment of respiratory failure due to trauma in the pediatric patient is possible by means of ECLS with acceptable survival.

\section{References}

1. Bartlett RH, Gazzaniga AB (1978) Extracorporeal circulation for cardiopulmonary failure. Curr Probs Surg 15: 4-96

2. Bartlett RH, Gazzaniga AB, Fong SW, Jeffries MR, Roohk HV, Haiduc N (1977) Extracorporeal membrane oxygenation support for cardiopulmonary failure. J Thorac Cardiovasc Surg 73: 375-386

3. Bartlett RH, Gazzaniga AB, Wetmore NE, Rucker R, Huxtable RF (1980) Extracorporeal membrane oxygenation (ECMO) in the treatment of cardiac and respiratory failure in children. Trans Am Soc Artif Int Organs 26: 578-579

4. Durandy Y, Batisse A, Chevalier JY (1988) A new extracorporeal assist device - initial clinical experience in pediatric patients. Int Care Med 14 (Supp. I): 268

5. ECMO Registry, University of Michigan Medical Center, Ann Arbor, Michigan, as of January 1990

6. Gattinoni L, Pesenti A, Mascheroni D, Marcolin R, Fumagali R, Rossi F, Iapichino G, Romagnoli G, Uziel L, Agostoni A, Kolobow T, Damia G (1986) Low frequency positive-pressure ventilation with extracorporeal $\mathrm{Co}_{2}$ removal in severe acute respiratory failure. JAMA 256: $881-886$

7. Heiden D, Mielke Jr CH, Rodvien R, Hill JD (1975) Platelets, hemostasis, and thromboembolism during treatment of acute respiratory insufficiency with extracorporeal membrane oxygenation. J Thorac Cardiovasc Surg 70: 644-665

8. Hirschl RB, Bartlett RH (1987) Extracorporeal membrane oxygenation support in cardiorespiratory failure. Adv Surg 21: 189-212

9. Lamy M, Eberhart RC, Fallat RJ, Dietrich HP, Ratliff J, Hill JD (1975) Effects of extracorporeal membrane oxygenation (ECMO) on pulmonary hemodynamics, gas exchange and prognosis. Trans Am Soc Artif Int Organs 21: 188-198 
10. Moront MG, Katz NM, O'Connell J, Hoy GR (1988) The use of topical fibrin glue at cannulation sites in neonates. Surg Gynecol Obstet 166: $358-359$

11. Pesenti A, Kolobow T, Gattinoni L (1988) Extracorporeal respiratory support in the adult. Trans Am Soc Artif Int Organs 34: 1006-1008

12. Pyle RB, Helton WC, Johnson FW, Hornung JR, Hunt CE, Trumball HR, Lindsay WG, Nicoloff DM (1975) Clinical use of the membrane oxgenator. Arch Surg 110: 966-970

13. Redmond CR, Graves ED, Falterman KW, Ochsner JL, Arensman RM (1987) Extracorporeal membrane oxygenation for respiratory and cardiac failure in infants and children. J Thorac Cardiovase Surg 93: $199-204$
14. Snider MT, Campbell DB, Kofke WA, High KM, Russell GB, Keamy MF, Williams DR (1988) Venovenous perfusion of adults and children with severe acute respiratory distress syndrome: the Pennsylvania State University experience for 1982-1987. Trans Am Soc Artif Int Organs 34: 1014-1020

15. Zapol W, Pontoppidan H, McCullough N, Schmidt V, Bland J, Kitz $\mathrm{R}$ (1972) Clinical membrane lung support for acute respiratory insufficiency. Trans Am Soc Artif Int Organs 18: 553-560

16. Zapol WM, Snider MT, Hill JD, Fallat RJ, Bartlett RH, Edmunds LH, Morris AH, Pierce II EC, Thomas AN, Proctor HJ, Drinker PA, Pratt PC, Bagniewski A, Miller Jr RG (1979) Extracorporeal membrane oxygenation in severe respiratory failure: a randomized, prospective study. JAMA 242: 2193-2196 